\title{
Funding under threat in Japan
}

\author{
Japanese science is facing severe budget cuts that risk causing lasting damage.
}

Just as the Large Hadron Collider roared back to life in late November 2009, the near detector of the long-baseline T2K experiment in Japan was picking up its first neutrino signatures - the latest success in this effort to better understand neutrino oscillations by firing beams of neutrinos from the High Energy Accelerator Research Programme's (KEK) J-PARC accelerator complex to the Super-Kamiokande apparatus in the Kamioka mine, $295 \mathrm{~km}$ away (Nature Phys. 5, 527; 2009). But the jubilation of the Japanese researchers, and their international collaborators, was surely tempered by the news that KEK, and indeed all of Japanese science, is facing swingeing cuts in funding.

Following the election to government of the Democratic Party on 30 August ending 50 years of almost unbroken rule by the Liberal Democratic Party - all budget requests for the next financial year, beginning in April 2010, have come under review by the newly established Government Revitalization Unit. A huge saving, of more than US\$30 billion, is being sought nationally. In science, there could be body blows to some key facilities as well as to individual grants. The SPring- 8 synchrotron might be one outright casualty, while KEK, Super-Kamiokande and the Subaru telescope in Hawaii are threatened with cuts to their operating funds.

The next-generation supercomputer project at RIKEN, intended for the modelling of galaxy formation and of the climate on Earth, could also fall victim: the revitalization team is recommending a freeze of the US $\$ 290$ million budget request for 2010 , pending further review; US\$610 million has already been invested in the US $\$ 1.3$ billion project, and project leader Tadashi Watanabe has called the move "very short-sighted".

\section{the axe is set to fall fast - too fast surely for a careful assessment of where the waste really lurks}

Indeed, the Japanese science community has responded unusually vocally to the threatened cuts, calling also on the international community for support. Following a meeting of some 1,000 sympathizers at the University of Tokyo, a statement was issued by the eight Nobel prize winners living in Japan — including 2008 winner Makoto Kobayashi — in which the claim was made that, "For Japan, a country poor in resources, the weakening of our science and technology means the decay of our country."

Prime Minister Yukio Hatoyama has promised to take scientists' opinions into account. Less sympathy has been voiced by one member of the Government Revitalization Unit, Yoshihiro Katayama, who stresses, however, that the real objective is to cut bureaucratic waste. That is fair, and a natural action for the new-broom Democratic Party government. But the depth of the threatened cuts is of real concern: in slicing out the waste, good science risks being lost. And the axe is set to fall fast - too fast surely for a careful assessment of where the waste really lurks - as the government intends to finalize the budget in a matter of days, by the end of 2009 .

Not long ago, at J-PARC's inauguration, under secretary for science in the US Department of Energy, Steve Koonin spoke of "another great venture in Japanese science". What other great ventures might survive in Japanese science, we must now wait to see.

\section{Work in progress}

\section{Will Sesame Street, video games and robots get school children interested in science?}

"We will restore science to its rightful place." President Barack Obama’s explicit nod during his inauguration was eagerly welcomed by scientists. Now fresh applause has greeted the 'educate to innovate' campaign, launched by the president last month. A nationwide effort "to move American students to the top of the pack in science and math achievement over the next decade", the programme brings together businesses and non-profit groups to invest in the education of middle- and highschool students.

The purse holds over US\$260 million in total, including a commitment of US\$100 million from Time Warner Cable to produce shows that promote science and technology. Children's favourite
Sesame Street will have a two-year focus on science; Discovery Communications will deliver science content to 60,000 schools, reaching 35 million pupils; and electronics giant Sony will support a challenge to design free, science-based video games.

Further initiatives such as 'Connect a million minds' aim to encourage youngsters to explore science in a playful way after school, for example through robotics competitions (http://connectamillionminds. com). And National Lab Day, to be held during the first week of May 2010, will be the highlight of a project aimed at fostering collaboration between volunteers, students and educators (http://www.nationallabday. org). "Students will launch rockets, construct miniature windmills, and get their hands dirty. They'll have the chance to build and create - and maybe destroy just a little bit - to see the promise of being the makers of things, and not just the consumers of things", said Obama at the 'educate to innovate' launch event in Washington DC. The White House will also host an annual science fair.

'Educate to innovate' is an exciting, landmark programme. According to Obama: "We're going to show young people how cool science can be." But the challenge is in sustaining the effort, providing welleducated teachers and job prospects for those youngsters who do decide to pursue a career in science. The goal has to be greater than simply seeing US students excel in tests. 